\title{
Correction to: ESR1 mutations are frequent in newly diagnosed metastatic and loco- regional recurrence of endocrine-treated breast cancer and carry worse prognosis
}

Adi Zundelevich ${ }^{1 \dagger}$, Maya Dadiani ${ }^{1+}$, Smadar Kahana-Edwin ${ }^{1}$, Amit Itay $^{3}$, Tal Sella ${ }^{2,3}$, Moran Gadot ${ }^{3}$, Karen Cesarkas $^{4}$, Sarit Farage-Barhom ${ }^{4}$ Efrat Glick Saar ${ }^{4}$, Eran Eyal ${ }^{5}$, Nitzan Kol ${ }^{5}$, Anya Pavlovski ${ }^{6}$, Nora Balint-Lahat ${ }^{6}$, Daniela Dick-Necula ${ }^{6}$, Iris Barshack ${ }^{6,7}$, Bella Kaufman ${ }^{3,7}$ and Einav Nili Gal-Yam²,3*

\section{Correction to: Breast Cancer Res https://doi.org/10.1186/s13058-020-1246-5}

After the publication of the original article [1], we were notified the upper panel of the Fig. 1, where the patients' codes are listed, was cropped by mistake so the patients 18 are repeated. The 88 patients should be listed, instead.

Below is the correct version of Fig. 1.

\begin{abstract}
Author details
${ }^{1}$ Cancer Research Center, Sheba Medical Center, Tel-Hashomer, Israel. ${ }^{2}$ The Dr. Pinchas Borenstein Talpiot Medical Leadership Program, Chaim Sheba Medical Center, Ramat Gan, Israel. ${ }^{3}$ Breast Oncology Institute, Sheba Medical Center, Tel-Hashomer, Israel. ${ }^{4}$ NGS Unit, Cancer Research Center, Sheba Medical Center, Tel-Hashomer, Israel. ${ }^{5}$ Bioinformatics Unit, Cancer Research Center, Sheba Medical Center, Tel-Hashomer, Israel. ${ }^{6}$ Pathology Institute, Sheba Medical Center, Tel-Hashomer, Israel. ${ }^{7}$ Sackler Faculty of Medicine, Tel Aviv University, Tel Aviv, Israel.
\end{abstract}

Published online: 12 March 2020

\section{Reference}

1. Zundelevich, et al. ESR1 mutations are frequent in newly diagnosed metastatic and loco-regional recurrence of endocrine-treated breast cancer and carry worse prognosis. Breast Cancer Res. 2020;22:16. https://doi.org/10. 1186/s13058-020-1246-5.

The original article can be found online at https://doi.org/10.1186/s13058020-1246-5

* Correspondence: Einav.NiliGal-Yam@sheba.health.gov.l

${ }^{\dagger}$ Adi Zundelevich and Maya Dadiani contributed equally to this work.

${ }^{2}$ The Dr. Pinchas Borenstein Talpiot Medical Leadership Program, Chaim Sheba Medical Center, Ramat Gan, Israel

${ }^{3}$ Breast Oncology Institute, Sheba Medical Center, Tel-Hashomer, Israel

Full list of author information is available at the end of the article

C C The Author(s). 2020 Open Access This article is licensed under a Creative Commons Attribution 4.0 International License, which permits use, sharing, adaptation, distribution and reproduction in any medium or format, as long as you give appropriate credit to the original author(s) and the source, provide a link to the Creative Commons licence, and indicate if changes were made. The images or other third party material in this article are included in the article's Creative Commons licence, unless indicated otherwise in a credit line to the material. If material is not included in the article's Creative Commons licence and your intended use is not permitted by statutory regulation or exceeds the permitted use, you will need to obtain permission directly from the copyright holder. To view a copy of this licence, visit http://creativecommons.org/licenses/by/4.0/ The Creative Commons Public Domain Dedication waiver (http://creativecommons.org/publicdomain/zero/1.0/) applies to the data made available in this article, unless otherwise stated in a credit line to the data. 


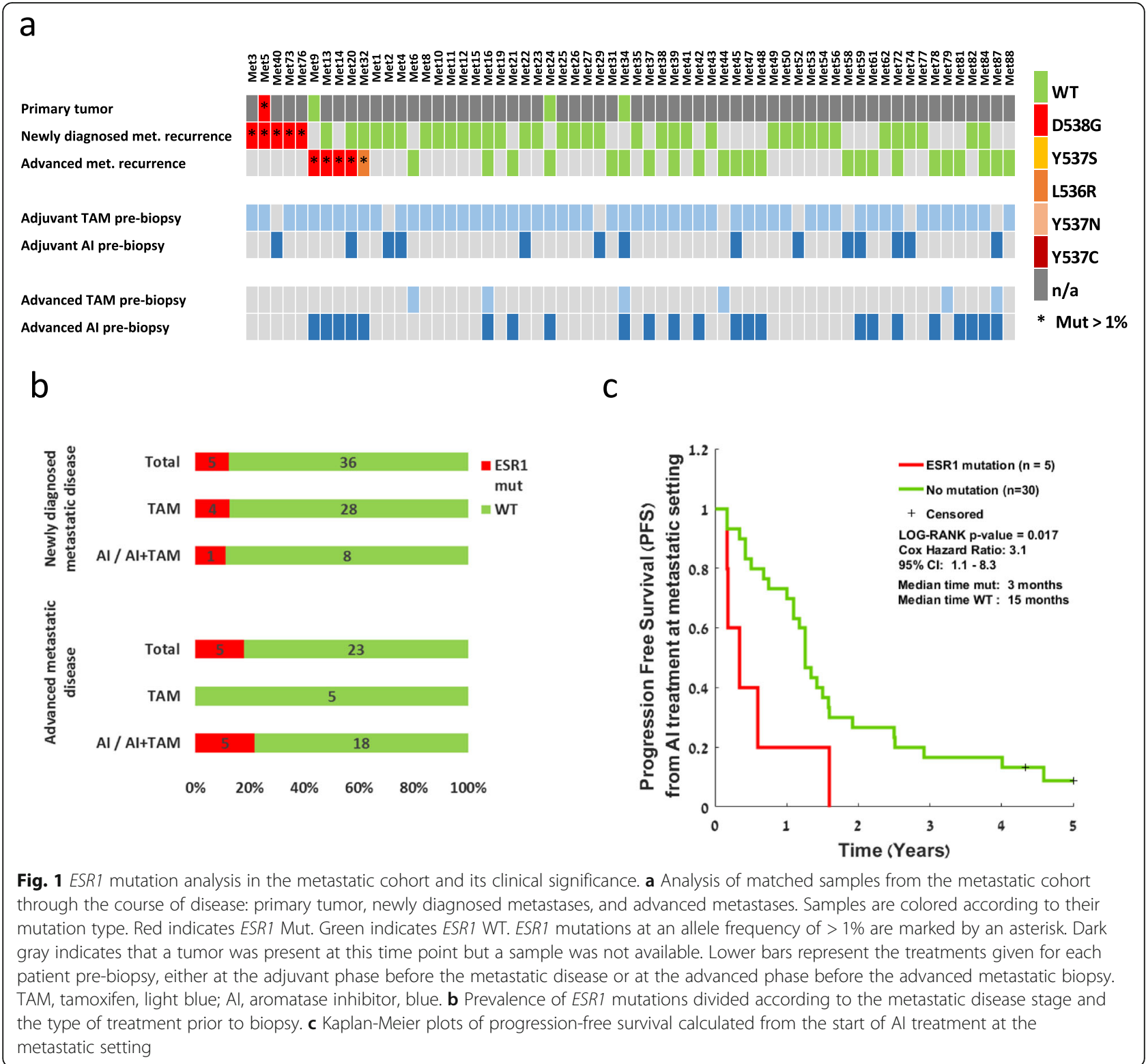

